\title{
Short telomeres increase the risk of severe COVID-19
}

Research Paper

\author{
Antoine Froidure ${ }^{1,2,}{ }^{*}$, Manon Mahieu ${ }^{3, *}$, Delphine Hoton ${ }^{4,2}$, Pierre-François Laterre ${ }^{5,2}$, Jean Cyr \\ Yombi $^{6,2}$, Sandra Koenig', Benoit Ghaye ${ }^{7,2}$, Jean-Philippe Defour ${ }^{8,3, \#}$, Anabelle Decottignies ${ }^{3, \#}$ on \\ behalf of the TELECOVID Investigators
}

\author{
${ }^{1}$ Department of Pulmonology, Cliniques universitaires Saint-Luc, Université Catholique de Louvain, Brussels, \\ Belgium \\ ${ }^{2}$ Institut de Recherche Expérimentale et Clinique, Université Catholique de Louvain, Brussels, Belgium \\ ${ }^{3}$ de Duve Institute, Université Catholique de Louvain, Brussels, Belgium \\ ${ }^{4}$ Department of Pathology, Cliniques Universitaires Saint-Luc, Université Catholique de Louvain, Brussels, \\ Belgium \\ ${ }^{5}$ Department of Intensive Care, Cliniques Universitaires Saint-Luc, Université Catholique de Louvain, Brussels, \\ Belgium \\ ${ }^{6}$ Department of Internal Medicine and Infectious Diseases, Cliniques Universitaires Saint-Luc, Université \\ Catholique de Louvain, Brussels, Belgium \\ ${ }^{7}$ Department of Radiology, Cliniques Universitaires Saint-Luc, Université Catholique de Louvain, Brussels, \\ Belgium \\ ${ }^{8}$ Department of Laboratory Hematology, Cliniques Universitaires Saint-Luc, Université Catholique de Louvain, \\ Brussels, Belgium \\ *Co-first authors \\ ${ }^{\#}$ Co-senior authors
}

Correspondence to: Antoine Froidure; email: antoine.froidure@uclouvain.be

Keywords: COVID-19, telomere length

Received: August 3, $2020 \quad$ Accepted: September 8, 2020 Published: October, 262020

Copyright: (c) 2020 Froidure et al. This is an open access article distributed under the terms of the Creative Commons Attribution License (CC BY 3.0), which permits unrestricted use, distribution, and reproduction in any medium, provided the original author and source are credited.

\section{ABSTRACT}

Telomeres are non-coding DNA sequences that protect chromosome ends and shorten with age. Short telomere length (TL) is associated with chronic diseases and immunosenescence. The main risk factor for mortality of coronavirus disease 2019 (COVID-19) is older age, but outcome is very heterogeneous among individuals of the same age group. Therefore, we hypothesized that TL influences COVID-19-related outcomes.

In a prospective study, we measured TL by Flow-FISH in 70 hospitalized COVID-19 patients and compared TL distribution with our reference cohort of 491 healthy volunteers. We also correlated TL with baseline clinical and biological parameters. We stained autopsy lung tissue from six non-survivor COVID-19 patients to detect senescence-associated $\beta$-galactosidase activity, a marker of cellular aging.

We found a significantly higher proportion of patients with short telomeres $\left(<10^{\text {th }}\right.$ percentile) in the COVID-19 patients as compared to the reference cohort $(\mathrm{P}<0.001)$. Short telomeres were associated with a higher risk of critical disease, defined as admission to intensive care unit (ICU) or death without ICU. TL was negatively correlated with C-reactive protein and neutrophil-to-lymphocyte ratio. Finally, lung tissue from patients with very short telomeres exhibit signs of senescence in structural and immune cells.

Our results suggest that $T L$ influences the severity of the disease. 


\section{INTRODUCTION}

Telomeres are specialized structures that, through the formation of a loop, protect chromosome ends from DNA damage response activation [1]. Telomeres progressively shorten with age, leading to the loss of chromosome end protection and the activation of a p53dependent DNA damage response that triggers senescence or apoptosis [2, 3]. Short telomeres are associated with a higher risk of aplasia and lung fibrosis, probably linked to early progenitor cell exhaustion $[4,5]$. More recently, several studies have demonstrated the impact of shorter telomeres on immune cell function, a phenomenon referred to as immunosenescence. Immunosenescence is an age-dependent process associated with the progressive depletion of naïve T cells and the reduced proliferation ability of $\mathrm{T}$ cell that likely impact immune surveillance against persistent viral infections like Cytomegalovirus (CMV) in the elderly $[6,7]$. A recent report established that abnormally short telomeres in patients with telomere-related gene mutations are sufficient to drive $\mathrm{T}$ cell aging, although additional and still undefined telomere lengthindependent molecular programs further contribute to immunosenescence in the elderly [8].

Other recent data support a role for telomeres in defense against pathogens: adults with shorter telomeres are more sensitive to experimentally-induced respiratory viral infection [9]. Along the same lines, short leukocyte telomere length (TL) was associated with more severe acute respiratory distress syndrome and worse survival in patients with sepsis [10].

Outcome of the current coronavirus disease 19 (COVID-19) pandemic is highly heterogeneous, ranging from asymptomatic people to patients hospitalized in intensive care units (ICU) with need of mechanical ventilation and eventual fatal outcome due to respiratory failure. To date, the strongest risk factor associated with severe disease and death in COVID-19 is older age [11], with infection fatality rate ranging from eight to $36 \%$ in people aged $\geq 80$ years [12]. Yet, studies performed exclusively in younger hospitalized patients -representing the most severely ill patients- reported similar fatality ratios of $8-28 \%$, suggesting that age is not the only factor modulating COVID-19 outcome [12]. Lymphopenia is another risk factor for poor outcome, pointing towards a potential role for telomere modulation in COVID-19 $[13,14]$.

Based on the above, we hypothesized that shorter TL might be linked to poorer outcome in COVID-19 and addressed this hypothesis in a prospective cohort of hospitalized patients.

\section{RESULTS}

\section{Study population}

We prospectively recruited 70 patients hospitalized in COVID-19 dedicated units between April $7^{\text {th }}$ and May $27^{\text {th }}$, 2020, during the main wave of COVID-19 in Belgium. The clinical characteristics of our patients are provided in Table 1. Our cohort included 48 men (68.6\%). Median age was 63 years-old (range 27-96). Fifty-three $(75.7 \%)$ patients had at least one chronic disease including hypertension $(22,31.4 \%)$, previously documented hypercholesterolemia $(20,28.6 \%)$, diabetes $(13,18.6 \%)$, obesity defined as a BMI $>30 \mathrm{~kg} / \mathrm{m}^{2}(9$, $12.9 \%)$ or ischemic cardiovascular disease $(8,11.4 \%)$. Twenty-five patients $(35.7 \%)$ were current or exsmokers. At the day of admission in the hospital (baseline), no patient had received any COVID-19related treatment. During their hospitalization, a majority of subjects received hydroxychloroquine $(59,84.3 \%)$, as this drug was at that time recommended for hospitalized patients in Belgium. Eleven patients (15.7\%) experienced a thrombotic event requiring therapeutic anticoagulation (five deep venous thrombosis, three arterial thrombosis, two ischemic strokes and one pulmonary embolism). During hospitalization, median peak oxygen flow was 10 liter/minute administered through a mask, which corresponds to a fraction of inspired oxygen of about 0.9 . Fourteen patients $(20 \%)$ beneficiated from continuous positive airway pressure (CPAP).

Thirty-three patients $(47.1 \%)$ were admitted in intensive care, of whom 30 patients required mechanical ventilation $(42.8 \%)$. Nine patients $(12.9 \%)$ benefited from extra-corporeal membrane oxygenation (ECMO). Eighteen patients (25.7\%) died from COVID-19.

\section{Increased frequency of short telomere individuals in hospitalized COVID-19 patients}

We measured TL in leucocytes using the Flow-FISH technique [15]. Figure 1A shows the distribution of individuals within the indicated percentile ranges of TL. When compared to the reference cohort, we found a clear enrichment of patients with telomeres $<\mathrm{P} 10$ $(\mathrm{N}=28,40.0 \%$, Figure $1 \mathrm{~B}(\mathrm{p}<0.0001$, Chi-Square test $))$, indicating that hospitalized COVID-19 patients display significantly shorter telomeres than the reference population.

\section{Short telomeres are associated with a higher risk of unfavorable COVID-19 outcome and correlate with prognostic biological factors}

We segregated our population based on short $\left(<10^{\text {th }}\right.$ percentile, P10) or normal $(\geq \mathrm{P} 10)$ telomere length 
Table 1. Clinical characteristics of the TELECOVID cohort (all values are median and range, unless specified).

\begin{tabular}{|c|c|}
\hline \multicolumn{2}{|l|}{ Baseline clinical features } \\
\hline Age (years) & $63(27-96)$ \\
\hline Sex ratio $(\mathrm{M} / \mathrm{F})$ & $48 / 22$ \\
\hline Current or ex-smokers $(\mathrm{N}, \%)$ & $25(35.7 \%)$ \\
\hline Hypertension & $22(31.4 \%)$ \\
\hline Known hypercholesterolaemia (N, \%) & $20(28.6 \%)$ \\
\hline Diabetes & $13(18.6 \%)$ \\
\hline Obesity $\left(\mathrm{BMI}>30 \mathrm{~kg} / \mathrm{m}^{2}\right)(\mathrm{N}, \%)$ & $9(12.9 \%)$ \\
\hline Ischemic cardiovascular disease & $8(11.4 \%)$ \\
\hline Symptoms duration prior to admission (days) & $7(1-15)$ \\
\hline Disease extend on HRCT $(\%)^{*}$ & $20.61(0.47-68.78)$ \\
\hline \multicolumn{2}{|l|}{ Baseline biological features } \\
\hline $\mathrm{CRP}(\mathrm{mg} / \mathrm{L})$ & $95.95(1.3-353.2)$ \\
\hline LDH (IU/L) & $372(162-1855)$ \\
\hline ASAT/GOT (U/L) & $41(8-242)$ \\
\hline $\begin{array}{l}\mathrm{PaO}_{2} \text { with fraction of inspired oxygen } 0.21 \\
\text { (ambient air, } \mathrm{mmHg} \text { ) }\end{array}$ & $64.5(26-134)$ \\
\hline Blood lymphocytes $\left(x 10^{3} / \mu \mathrm{L}\right)$ & $0.68(0.17-2.13)$ \\
\hline Blood neutrophils $\left(\times 10^{3} / \mu \mathrm{L}\right)$ & $4.99(0.48-15.91)$ \\
\hline Neutrophils/lymphocytes ratio & $6.03(0.86-50.57)$ \\
\hline Eosinophils (x103/ $\mu \mathrm{L})$ & $0(0-0.18)$ \\
\hline \multicolumn{2}{|l|}{ COVID-19 management characteristics } \\
\hline Hospitalisation duration (days) ${ }^{\dagger}$ & $19.5(4-102)$ \\
\hline Specific treatment $(\mathrm{N}, \%)$, including & $59(84.3 \%)$ \\
\hline - Hydroxychloroquine (N, \%) & - $59(84.3 \%)$ \\
\hline - $\quad$ Systemic corticosteroids $(\mathrm{N}, \%)$ & $-\quad 5(7.1 \%)$ \\
\hline - $\quad$ Others $(\mathrm{N}, \%)$ & $-\quad 3(4.2 \%) \div$ \\
\hline Admission in ICU $(\mathrm{N}, \%)$ & $33(47.1 \%)$ \\
\hline Days in ICU $\ddagger$ & $23(2-70)$ \\
\hline Death $(\mathrm{N}, \%)$ & $18(25.7 \%)$ \\
\hline
\end{tabular}

*: absence of baseline HRCT for 8 patients.

t: 2 missing data (patients still hospitalised).

¥: 1 patients received an anti-IL-6 monoclonal antibody, 2 patients received azithromycin.

(Table 2). Twenty-eight (40\%) patients had a TL<P10 and 42 had a $\mathrm{TL} \geq \mathrm{P} 10$.

We found that $\mathrm{TL}<\mathrm{P} 10$ was significantly associated with a greater risk to develop a critical disease, namely being admitted in ICU or death without ICU (composite endpoint), OR 3.24 (CI 1.21-8.55, $\mathrm{P}=0.02$, Chi-square test Figure 1C). We also built a Kaplan-Meyer curve of our populations, showing time elapsed prior to critical disease. There was a significant difference between patients with $\mathrm{TL}<\mathrm{P} 10$ and patients with $\mathrm{TL} \geq \mathrm{P} 10$ as shown in Figure 1D. There was also a trend for higher mortality in the TL $<\mathrm{P} 10$ group as compared to patients with $\mathrm{TL} \geq \mathrm{P} 10$, but this was not statistically significant
(32.1\% VS 21.4\%, $\mathrm{P}=0.16$ ). Furthermore, TL (in percentiles) negatively correlated with hospitalization duration (Spearman $\mathrm{r}=-0.248, \mathrm{P}=0.041$ ). Importantly, there was no significant difference of age between patients with telomeres $<\mathrm{P} 10$ and $\geq \mathrm{P} 10$ (Median age 64 VS 62.5, $\mathrm{P}=0.21$, Table 2). As shown in Table 2, neutrophil-to-lymphocyte ratio (NLR) was significantly higher in patients with TL below 10, although neutrophil counts were similar. So, the significant difference in NLR was mainly driven by lymphopenia.

We then studied the correlation between TL (expressed in percentile) and biological factors previously associated with poorer COVID-19 outcome, namely 
C-reactive protein level (CRP), lymphocyte count, NLR and eosinophils. We found a moderate but statistically significant correlation between TL and CRP (Spearman $r=-0.259, P=0.03$ ) and NLR (Spearman $r=-0.268$, $\mathrm{P}=0.025)$, meaning that the lower the TL, the higher the CRP and NLR. There was a trend for a significant correlation between $\mathrm{TL}$ and lymphocyte count (Spearman $\mathrm{r}=0.197, \mathrm{P}=0.11$ ), suggesting that the longer the telomeres, the higher the blood lymphocytes at admission.

TL is not correlated with high resolution computed tomography (HRCT) extend of COVID-19-related lesions

Out of the 70 patients, $62(88.6 \%)$ underwent a HRCT on the day of admission. We compared the extent of lesion on HRCT (percentage opacity score) at

A

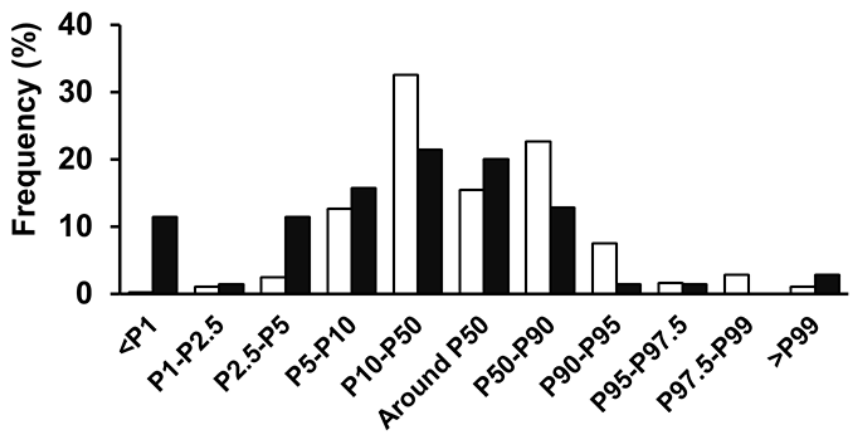

口TL expected घTL COVID

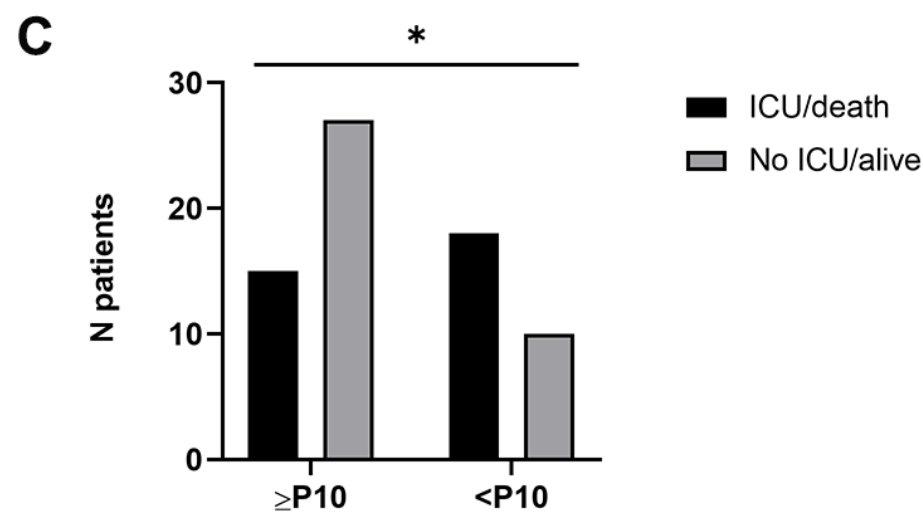

Telomere length (percentile) admission between patients with $\mathrm{TL}<\mathrm{P} 10$ and $\geq \mathrm{P} 10$ (median, range) and did not find any difference between both groups $(23.8 \%, 2.3-68.8 v s .18 .6 \%, 0.5-68.4$, $\mathrm{P}=0.41$, Mann-Whitney $U$ test).

\section{Increased cellular senescence in lungs from COVID- 19 patients with very short telomeres}

To evaluate whether short telomeres of COVID-19 patients may be associated with immune cell senescence, we evaluated SA- $\beta$-gal activity in lungs from non-survivor patients. Our results revealed high levels of SA- $\beta$-gal activity in both immune and structural lung cells from two COVID-19 patients of 55 and 74 years old with TL below the first percentile (P1) (Figure $2 \mathrm{~A}$ ). We did not detect any SA- $\beta$-gal activity in the lung of another 55 years old deceased COVID-19 patient with telomeres lying in the P50-P90 range

B
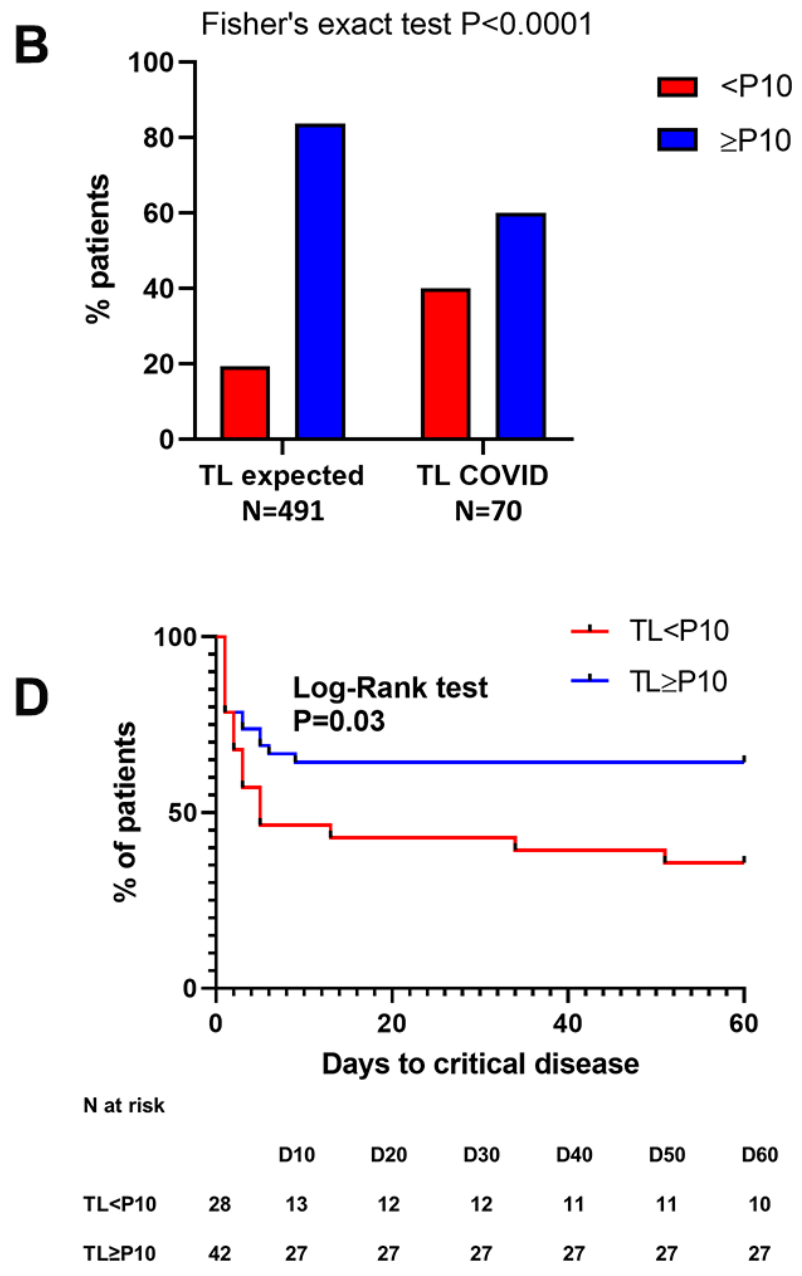

Figure 1. High proportion of COVID-19 patients with short telomeres and link with outcome. (A) As compared to the reference population (white bars), we found an enrichment of COVID-19 patients with short telomeres (black bars). (B) There is a statistically significant association between short telomeres ( $<$ P10) and COVID-19 (Chi-square test, P<0.0001). (C) There is a statistically significant association between short telomeres (<P10) and unfavorable outcome (admission in ICU and/or death) in COVID-19 hospitalized patients (Chi-square test, $\mathrm{P}=0.02$ ). (D) Kaplan-Meyer curve showing the time to admission in ICU and/or death without in patients with $T L<P 10$ or $\geq P 10$. 
Table 2. Comparison of key clinical and biological features between patients with telomere length below and equal or above the $10^{\text {th }}$ percentile.

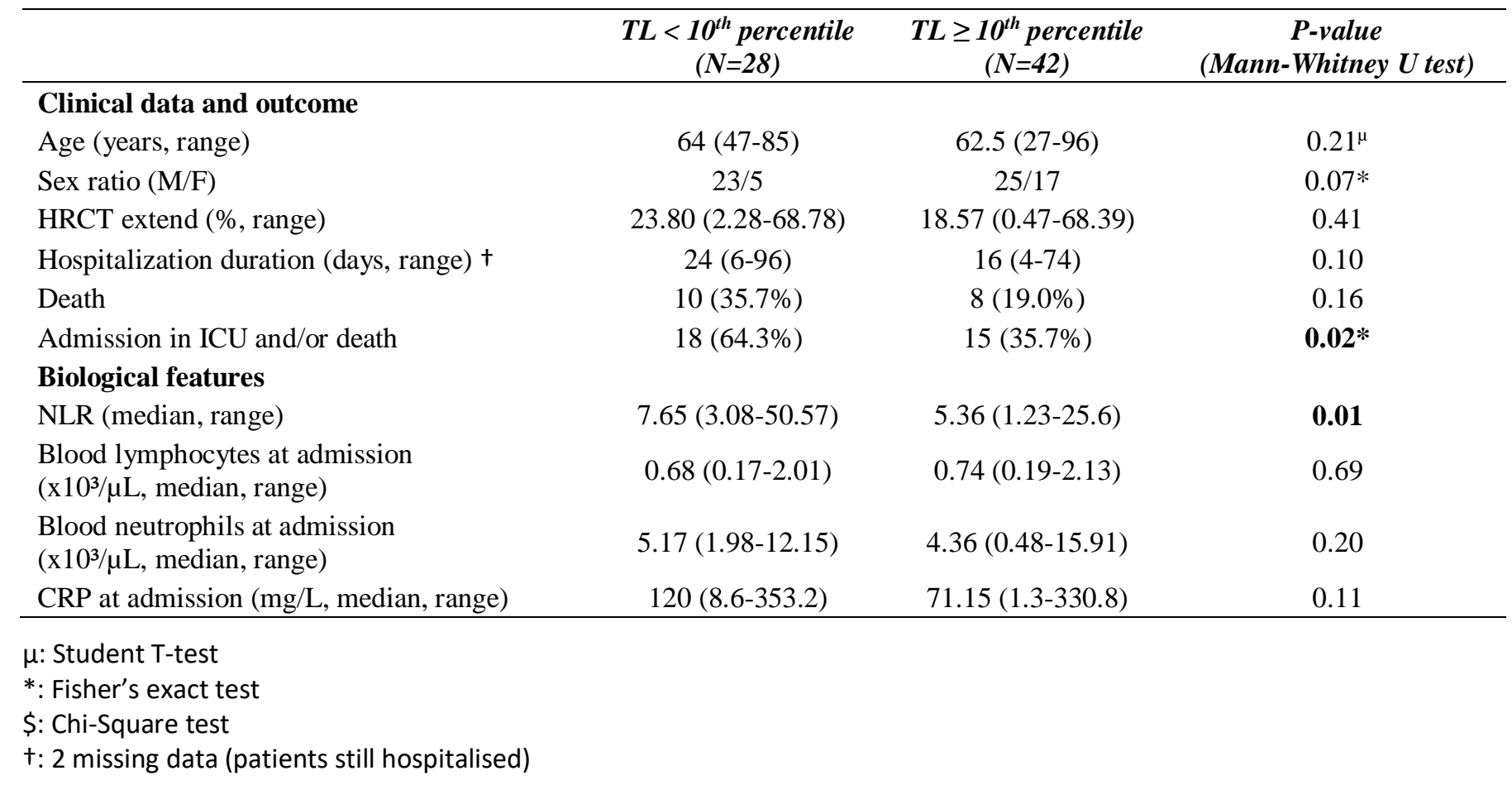

(Figure 2A). In the remaining lungs from deceased patients with TL >P1, low to moderate levels of SA- $\beta$-gal activity were detected (Figure 2A, 2B). As previously demonstrated [16], negative controls obtained from healthy lung tissues of donors aged 38-82 years old did not reveal any SA- $\beta$-gal activity (Figure 2A, 2B).

\section{DISCUSSION}

Our study in a cohort of 70 hospitalized COVID-19 patients revealed an enrichment for individuals with short telomeres in comparison with the reference population. Furthermore, short telomeres $(<\mathrm{P} 10)$ were associated with a higher risk of admission in ICU and/or death independently of age. TL was significantly correlated to CRP and neutrophil-to-lymphocyte ratio, both factors previously associated with poorer COVID-19 outcome [13]. Finally, we found evidence of senescence in both structural and immune cells in the lungs of very short telomere $(<\mathrm{P} 1)$ patients who died from COVID-19. Altogether, our findings support the hypothesis that TL modulates COVID-19 outcome and may partially explain the high variability of COVID-19 outcome among individuals of similar age. The mild correlations between TL and biological factors in our cohort suggest that TL is probably one feature, among others, such as variants in immune-related genes, type 2 angiotensin convertase enzyme [17] or variations in the
ABO blood-group system, that underpin impaired inflammatory response towards coronavirus 2 . On the contrary, we did not find any link between TL and extent of lesion on HRCT, although the latter is a major determinant of COVID-19-related mortality. This is probably because ground glass opacities and condensations, key radiological features on HRCT [18], do not only reflect the presence of inflammation but also edema, bronchiolitis and ventilation defects.

The progressive shortening of lymphocyte telomeres with aging has been proposed to contribute to the ageassociated defects of immunity and the higher risk of long-term infection with CMV [6] and mortality [19]. Conversely, healthy elderly exhibit longer telomeres than their peers do $[20,21]$. Beyond COVID-19 and other viral diseases, differences in TL and telomere homeostasis may underlie impaired immune response towards various pathogens, as illustrated by the recent demonstration that sepsis outcome was also linked to TL [10].

We [22] and others previously showed that prematurely aged skin fibroblasts from patients with abnormally short telomeres display increased SA- $\beta$-gal activity, a marker first described in senescent skin fibroblasts and keratinocytes. Here, we only found signs of senescence in the lungs of non-survivors with very short telomeres $(<\mathrm{P} 1)$ and not in either patients with normal TL or aged 
A

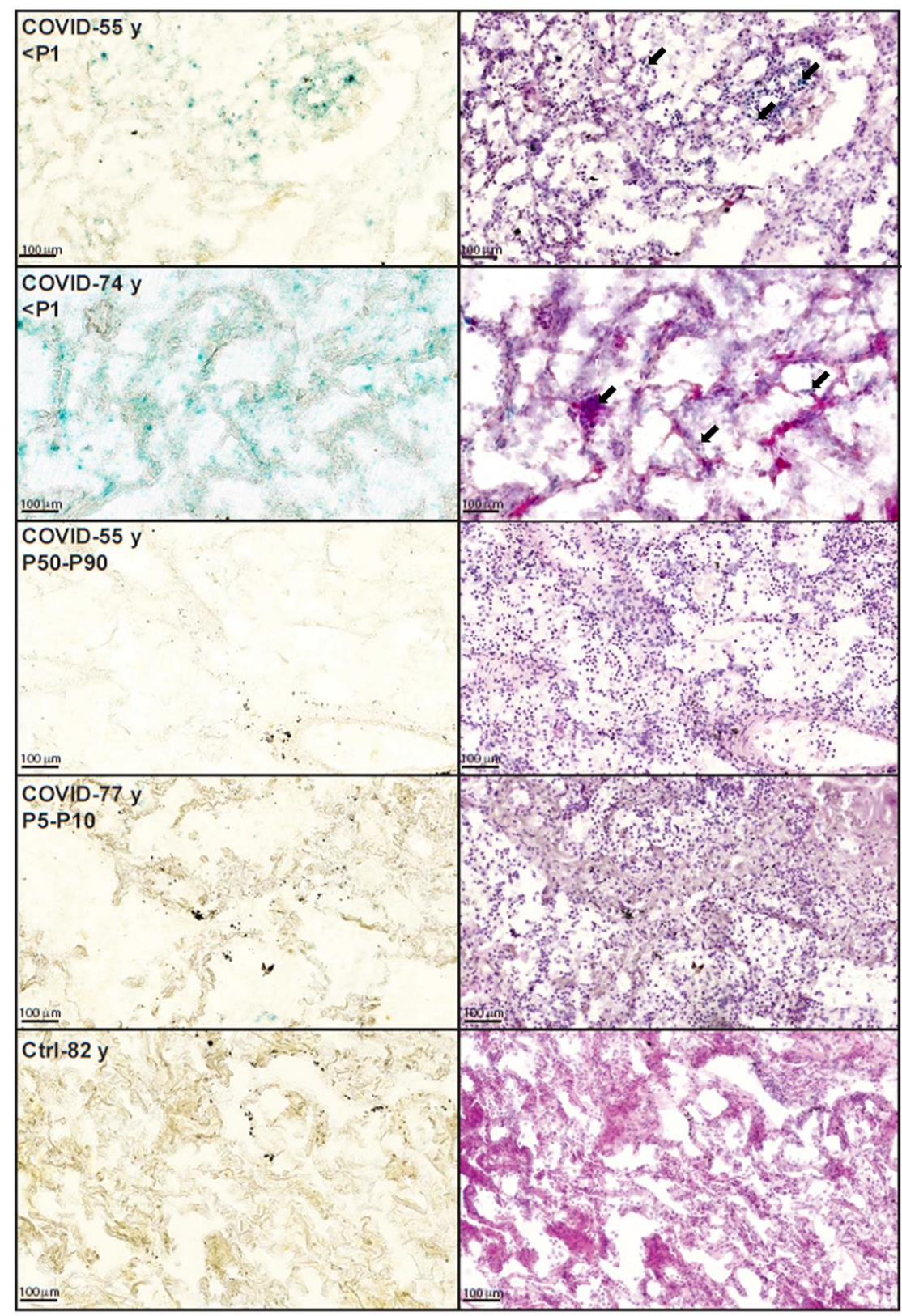

$++$
B Sample

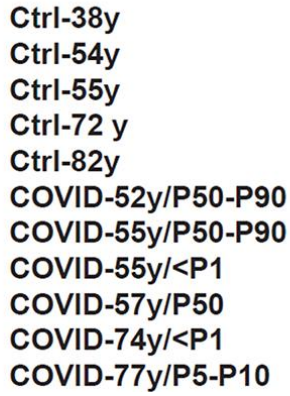

SA- $\beta$-Gal activity

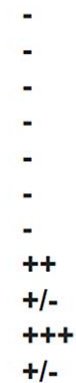

Figure 2. SA- $\beta$-Gal staining of lung slices from COVID-19 and control patients. (A) SA- $\beta$-Gal staining (left) and HE staining (right) of four COVID-19 lungs and one control lung. We only found signs of senescence (blue staining) in lungs from individuals with very short telomeres (<P1), both in structural and immune cells (black arrows). Conversely, staining was weak for a patient with short telomeres and absent for patients with normal TL and in control tissue. (B) overview of detected SA- $\beta$-Gal activity within analyzed samples. 
controls, which further illustrates that the observed senescence in the two COVID-19 patients with TL $<$ P1 is linked to the presence of very short telomeres, and not to age. Of note, we cannot exclude that lung senescence was a pre-existing condition in these patients with very short telomeres, but neither of these patients had a preexisting lung condition. So, based on our observations, it is very unlikely that lung senescence constitutes a driver for COVID-19, but it may have been an aggravating factor in those two patients.

Short telomeres also possibly impact COVID-19 outcome through the modulation of cytokine production, as illustrated by our finding that TL correlated with NLR, which constitutes a prognostic factor in multiple diseases [23], and CRP. Along this line, the increased transcription of short telomeres into TERRA non-coding RNAs was reported to promote IL-6 and TNF- $\alpha$ secretion [24, 25]. Short telomeres have also been associated with an increased transcription of ISG15 [26], a gene related to Type 1 interferon signaling. Hence, short telomeres may also possibly contribute to the harmful cytokine storm of COVID-19 patients.

As a limitation, our cohort was composed of severely to critically ill patients, with about a half of them being admitted to ICU and a fatality rate of $25.6 \%$. Therefore, whether our result may apply to the overall population of COVID-19 patients still needs to be confirmed.

In conclusion, we uncovered a link between telomere length and COVID-19 outcome, with a potential impact of TL on biological parameters. Altogether, our study paves the way for further investigations on a potential interest of TL as a prognostic factor of COVID-19. Whether TL may influence long-term outcome like lung fibrosis is also unknown at this point.

\section{MATERIALS AND METHODS}

\section{Study design}

The TElomere LEngth in COronaVIrus Disease 2019 (TELECOVID) trial is a single-center prospective trial. We prospectively included patients admitted in our dedicated COVID-19 units that fulfilled the following criteria: evidence of COVID-19 defined as the combination of a positive PCR on nasopharyngeal swab and lung infiltrates on high resolution computed tomography (HRCT) or chest X-ray at admission. All patients underwent blood sampling for TL measurement on peripheral blood granulocytes. We collected clinical, biological and radiological data on the day of admission in the hospital. We quantified the extension of lesions on admission HRCT with the CT Pneumonia Analysis software (Siemens Helthineers, Forchheim, Germany) and obtained a percentage opacity score, defined as the percentage of predicted volume of abnormalities compared to the total lung volume.

TL measurements obtained in COVID-19 patients were compared to those of a reference cohort of 491 healthy volunteers (from 0 to 99 years) obtained in the Cliniques Universitaires Saint-Luc (ISO15189).

We have conducted this cohort study in accordance with STROBE statement (https://www.strobe-statement.org/ index.php?id=strobe-home).

\section{Study objectives}

Our primary objectives were to measure telomere length in hospitalized COVID-19 patients and compare it to nomograms from our reference population and to study the potential association between short telomeres (below tenth percentile -P10) and unfavorable COVID-19 outcome, defined as admission in ICU and/or death without ICU (critical disease, according to the definition of NIH, covid19treatmentguidelines.nih.gov/overview/ management-of-covid-19/). Our secondary objectives were to correlate TL to baseline (at the day of admission in hospital) biological and radiological features. Finally, we sought to detect signs of senescence in lung samples from deceased COVID-19 patients.

\section{Blood sample processing and telomere length (TL) measurement}

TL was measured by Flow-FISH, currently considered as the gold standard technique [27]. The severe lymphopenia of most COVID-19 patients, together with the possible acute infection-driven shortening of telomeres in $\mathrm{T}$ lymphocytes, support the measurement of $\mathrm{TL}$ in the granulocytes rather than the lymphocytes. To confirm that granulocyte TL properly reflects lymphocyte TL, we compared their respective percentile ranges for individuals of the cohort. We found a good consistency between the two cell populations as, for nearly $60 \%$ of the individuals of the cohort, the percentile range was the same while, for $33 \%$ of them, only one category difference was observed (Supplementary Figure 1). Hence, for the large majority of individuals, granulocyte TL properly reflects lymphocyte TL.

All TL measurements were performed in duplicate in the Cliniques Universitaires Saint-Luc through Flow-FISH as described previously [15]. After red blood cell lysis with ammonium chloride as described in [15], white blood cells were frozen at $-80^{\circ} \mathrm{C}$ until analysis. Aliquots of calf thymus were mixed to each sample for internal control. Telomeres were stained with FITC-labelled 
$(\mathrm{CCCTAA})_{3}$ PNA probe (Panagene) and fluorescence was measured with a Navios EX flow cytometer (Beckman Coulter).

\section{Senescence-associated- $\beta$-galactosidase activity in lung tissues}

We had access to autopsy lung tissue from COVID-19 deceased patients and control lung tissue from our local biobank (IREC-PNEU). We slightly adapted the protocol previously described to perform senescenceassociated $\beta$-galactosidase (SA- $\beta$-Gal) [28]. Briefly, after fixation with $0.2 \%$ formaldehyde for $10 \mathrm{~min}$, $16 \mu$ m-thick sections of snap-frozen lung tissues were rinsed with PBS before overnight incubation at $37^{\circ} \mathrm{C}$ in staining solution at $\mathrm{pH}$ 5.6. After scanning, slides were incubated overnight in PBS $1 \mathrm{x}$ at RT, rinsed with $\mathrm{ddH}_{2} \mathrm{O}$ and stained first with hematoxylin and then with eosin. After a new rinsing with water, tissues were dehydrated through a series of ethanol baths, from $30 \%$ to $100 \%$, before incubation in isopropanol and then xylene and, finally, mounting.

\section{Statistics}

We used Chi-Square and Fisher's exact test for associations and Spearman $R$ test for correlation analysis. We used Student $t$ test and Mann-Whitney $U$ test for single comparisons when appropriate. We performed a Kaplan-Meyer curve and used Log-Rank test for comparing populations. All statistics were performed on SPSS 25 software (IBM, Armonk, NY, USA) and GraphPad Prism 8.4.1 (Graphpad Software, San Diego, CA, USA). A P-value under 0.05 was considered significant.

\section{Ethical considerations}

All patients provided informed consent prior to inclusion. This study was approved by our internal review board (Comité d'éthique hospitalo-facultaire), approval number 2020/06AVR/200.

\section{AUTHOR CONTRIBUTIONS}

A. Froidure designed the study, supervised the recruitment of patients, conducted analysis and wrote the manuscript. J-P Defour and A. Decottignies supervised Flow-FISH and lung staining, conducted analysis and wrote the manuscript. M. Mahieu performed Flow-FISH and lung staining. D. Hoton analyzed lung slices. PF Laterre and JC Yombi reviewed the study design and supervised recruitment within their respective departments. S. Koenig collected clinical data and coordinated the recruitment of patients. B. Ghaye reviewed all high-resolution computed tomography
(HCT) and quantified lesion extend. All authors revised the manuscript.

\section{ACKNOWLEDGMENTS}

We are indebted to all the COVID-19 patients who volunteered for this study. We sincerely acknowledge the help from Nicolas Dauguet (de Duve Institute, Brussels) in setting up the FACS analyses for FlowFISH. We thank Mrs Leslie Gielens, Caroline Berghe, Marie-France Dujardin and Suzanne Renard for their help in the recruitment of patients admitted in ICU. We also wish to thank Mrs Carole Dekelver (Clinical Trial Center, Cliniques Universitaires Saint-Luc) for her support in setting up the study.

\section{CONFLICTS OF INTEREST}

None of the authors has any conflicts of interest related to the present work.

\section{FUNDING}

This work is supported by a grant from the Fondation Louvain (grant number M1.21221.004), Université catholique de Louvain, Belgium.

\section{REFERENCES}

1. de Lange T. Shelterin-mediated telomere protection. Annu Rev Genet. 2018; 52:223-47.

https://doi.org/10.1146/annurev-genet-032918021921 PMID:30208292

2. d'Adda di Fagagna F, Reaper PM, Clay-Farrace L, Fiegler H, Carr P, Von Zglinicki T, Saretzki G, Carter NP, Jackson SP. A DNA damage checkpoint response in telomereinitiated senescence. Nature. 2003; 426:194-98.

https://doi.org/10.1038/nature02118

PMID: 14608368

3. Hemann MT, Strong MA, Hao LY, Greider CW. The shortest telomere, not average telomere length, is critical for cell viability and chromosome stability. Cell. 2001; 107:67-77.

https://doi.org/10.1016/s0092-8674(01)00504-9 PMID:11595186

4. Armanios $\mathrm{M}, \mathrm{Blackburn} \mathrm{EH}$. The telomere syndromes. Nat Rev Genet. 2012; 13:693-704. https://doi.org/10.1038/nrg3246 PMID:22965356

5. Alder JK, Barkauskas CE, Limjunyawong N, Stanley SE, Kembou F, Tuder RM, Hogan BL, Mitzner W, Armanios M. Telomere dysfunction causes alveolar stem cell failure. Proc Natl Acad Sci USA. 2015; 112:5099-104. https://doi.org/10.1073/pnas.1504780112 PMID:25840590 
6. Wherry EJ, Kurachi M. Molecular and cellular insights into T cell exhaustion. Nat Rev Immunol. 2015; 15:486-99. https://doi.org/10.1038/nri3862 PMID:26205583

7. Fülöp T, Larbi A, Pawelec G. Human T cell aging and the impact of persistent viral infections. Front Immunol. 2013; 4:271.

https://doi.org/10.3389/fimmu.2013.00271

PMID:24062739

8. Wagner CL, Hanumanthu VS, Talbot CC Jr, Abraham RS, Hamm D, Gable DL, Kanakry CG, Applegate CD, Siliciano J, Jackson JB, Desiderio S, Alder JK, Luznik L, Armanios M. Short telomere syndromes cause a primary T cell immunodeficiency. J Clin Invest. 2018; 128:5222-34.

https://doi.org/10.1172/JCI120216 PMID: $\underline{30179220}$

9. Cohen S, Janicki-Deverts D, Turner RB, Casselbrant ML, Li-Korotky HS, Epel ES, Doyle WJ. Association between telomere length and experimentally induced upper respiratory viral infection in healthy adults. JAMA. 2013; 309:699-705.

https://doi.org/10.1001/jama.2013.613

PMID:23423415

10. Liu S, Wang C, Green G, Zhuo H, Liu KD, Kangelaris KN, Gomez A, Jauregui A, Vessel K, Ke S, Hendrickson C, Matthay MA, Calfee CS, et al. Peripheral blood leukocyte telomere length is associated with survival of sepsis patients. Eur Respir J. 2020; 55:1901044.

https://doi.org/10.1183/13993003.01044-2019 PMID:31619475

11. Docherty $A B$, Harrison $E M$, Green $C A$, Hardwick $H E$, Pius R, Norman L, Holden KA, Read JM, Dondelinger F, Carson G, Merson L, Lee J, Plotkin D, et al, and ISARIC4C investigators. Features of 20133 UK patients in hospital with covid-19 using the ISARIC WHO clinical characterisation protocol: prospective observational cohort study. BMJ. 2020; 369:m1985.

https://doi.org/10.1136/bmj.m1985 PMID:32444460

12. Verity R, Okell LC, Dorigatti I, Winskill P, Whittaker C, Imai N, Cuomo-Dannenburg G, Thompson $\mathrm{H}$, Walker PG, Fu $H$, Dighe A, Griffin JT, Baguelin $M$, et al. Estimates of the severity of coronavirus disease 2019: a model-based analysis. Lancet Infect Dis. 2020; 20:669-77.

https://doi.org/10.1016/S1473-3099(20)30243-7 PMID:32240634

13. Jordan RE, Adab P, Cheng KK. Covid-19: risk factors for severe disease and death. BMJ. 2020; 368:m1198. https://doi.org/10.1136/bmj.m1198 PMID: $\underline{32217618}$

14. Aviv A. Telomeres and COVID-19. FASEB J. 2020; 34:7247-52.

https://doi.org/10.1096/fj.202001025 PMID: $\underline{32427393}$
15. Baerlocher GM, Vulto I, de Jong G, Lansdorp PM. Flow cytometry and FISH to measure the average length of telomeres (flow FISH). Nat Protoc. 2006; 1:2365-76.

https://doi.org/10.1038/nprot.2006.263 PMID:17406480

16. Minagawa $S$, Araya J, Numata $T$, Nojiri $S$, Hara $H_{\text {, }}$ Yumino Y, Kawaishi M, Odaka M, Morikawa T, Nishimura SL, Nakayama K, Kuwano K. Accelerated epithelial cell senescence in IPF and the inhibitory role of SIRT6 in TGF- $\beta$-induced senescence of human bronchial epithelial cells. Am J Physiol Lung Cell Mol Physiol. 2011; 300:L391-401.

https://doi.org/10.1152/ajplung.00097.2010

PMID:21224216

17. Cao $Y$, Li L, Feng $Z$, Wan $S$, Huang $P$, Sun $X$, Wen F, Huang $X$, Ning G, Wang W. Comparative genetic analysis of the novel coronavirus (2019-nCoV/SARSCoV-2) receptor ACE2 in different populations. Cell Discov. 2020; 6:11.

https://doi.org/10.1038/s41421-020-0147-1

PMID:32133153

18. Hu Q, Guan H, Sun Z, Huang L, Chen C, Ai T, Pan Y, Xia L. Early $C T$ features and temporal lung changes in COVID-19 pneumonia in Wuhan, China. Eur J Radiol. 2020; 128:109017.

https://doi.org/10.1016/j.ejrad.2020.109017 PMID:32387924

19. Cawthon RM, Smith KR, O'Brien E, Sivatchenko A, Kerber RA. Association between telomere length in blood and mortality in people aged 60 years or older. Lancet. 2003; 361:393-95.

https://doi.org/10.1016/S0140-6736(03)12384-7 PMID:12573379

20. Tedone E, Huang E, O'Hara R, Batten K, Ludlow AT, Lai TP, Arosio B, Mari D, Wright WE, Shay JW. Telomere length and telomerase activity in T cells are biomarkers of high-performing centenarians. Aging Cell. 2019; 18:e12859.

https://doi.org/10.1111/acel.12859

PMID:30488553

21. Steenstrup $T$, Kark JD, Verhulst $S$, Thinggaard $M$, Hjelmborg JV, Dalgård C, Kyvik KO, Christiansen L, Mangino M, Spector TD, Petersen I, Kimura M, Benetos $A$, et al. Telomeres and the natural lifespan limit in humans. Aging (Albany NY). 2017; 9:1130-42.

https://doi.org/10.18632/aging.101216 PMID:28394764

22. Benyelles M, Episkopou H, O'Donohue MF, Kermasson $L$, Frange $P$, Poulain F, Burcu Belen F, Polat M, BoleFeysot C, Langa-Vives F, Gleizes PE, de Villartay JP, Callebaut I, et al. Impaired telomere integrity and rRNA biogenesis in PARN-deficient patients and knock-out models. EMBO Mol Med. 2019; 11:e10201. 
https://doi.org/10.15252/emmm.201810201

PMID:31273937

23. Forget $P$, Khalifa $C$, Defour JP, Latinne $D$, Van Pel MC, De Kock $M$. What is the normal value of the neutrophilto-lymphocyte ratio? BMC Res Notes. 2017; 10:12. https://doi.org/10.1186/s13104-016-2335-5 PMID:28057051

24. Wang Z, Deng Z, Dahmane N, Tsai K, Wang P, Williams DR, Kossenkov AV, Showe LC, Zhang R, Huang Q, Conejo-Garcia JR, Lieberman PM. Telomeric repeatcontaining RNA (TERRA) constitutes a nucleoprotein component of extracellular inflammatory exosomes. Proc Natl Acad Sci USA. 2015; 112:E6293-300. https://doi.org/10.1073/pnas.1505962112 PMID:26578789

25. Arnoult N, Van Beneden A, Decottignies A. Telomere length regulates TERRA levels through increased trimethylation of telomeric H3K9 and HP1 $\alpha$. Nat Struct Mol Biol. 2012; 19:948-56.

https://doi.org/10.1038/nsmb.2364 PMID:22922742
26. Lou Z, Wei J, Riethman H, Baur JA, Voglauer R, Shay JW, Wright WE. Telomere length regulates ISG15 expression in human cells. Aging (Albany NY). 2009; 1:608-21.

https://doi.org/10.18632/aging.100066

PMID:20157543

27. Aubert G, Hills M, Lansdorp PM. Telomere length measurement-caveats and a critical assessment of the available technologies and tools. Mutat Res. 2012; 730:59-67.

https://doi.org/10.1016/j.mrfmmm.2011.04.003 PMID:21663926

28. Debacq-Chainiaux F, Erusalimsky JD, Campisi J, Toussaint $O$. Protocols to detect senescence-associated beta-galactosidase (SA-betagal) activity, a biomarker of senescent cells in culture and in vivo. Nat Protoc. 2009; 4:1798-806.

https://doi.org/10.1038/nprot.2009.191

PMID:20010931 


\section{SUPPLEMENTARY MATERIALS}

\section{TELECOVID Investigators}

\section{Frank Aboubakar ${ }^{1,2}$, Christophe Beauloye ${ }^{9,2}$, Leila Belkhir ${ }^{6,2}$, Emmanuel Coche ${ }^{7,2}$, Ludovic Gérard $^{5,2}$, Sophie Gohy,2, Luc-Marie Jacquet ${ }^{5,2}$, Giuseppe Liistro ${ }^{1,2}$, Amin Mahsouli,2, Benny Gimbada Mwenge $^{1,2}$, Thierry Pieters ${ }^{1,2}$, Charles Pilette ${ }^{1,2}$, Olivier Vancaeneghem ${ }^{5,2}$}

${ }^{1}$ Department of Pulmonology, Cliniques universitaires Saint-Luc, Université Catholique de Louvain, Brussels, Belgium

${ }^{2}$ Institut de Recherche Expérimentale et Clinique, Université Catholique de Louvain, Brussels, Belgium

${ }^{3}$ de Duve Institute, Université Catholique de Louvain, Brussels, Belgium

${ }^{4}$ Department of Pathology, Cliniques Universitaires Saint-Luc, Université Catholique de Louvain, Brussels, Belgium ${ }^{5}$ Department of Intensive Care, Cliniques Universitaires Saint-Luc, Université Catholique de Louvain, Brussels, Belgium

${ }^{6}$ Department of Internal Medicine and Infectious Diseases, Cliniques Universitaires Saint-Luc, Université Catholique de Louvain, Brussels, Belgium

${ }^{7}$ Department of Radiology, Cliniques Universitaires Saint-Luc, Université Catholique de Louvain, Brussels, Belgium ${ }^{8}$ Department of Laboratory Hematology, Cliniques Universitaires Saint-Luc, Université Catholique de Louvain, Brussels, Belgium

${ }^{9}$ Department of Cardiology, Cliniques Universitaires Saint-Luc, Université Catholique de Louvain, Brussels, Belgium 


\section{Supplementary Figure}

\section{A}

\begin{tabular}{|c|c|c|c|c|c|c|c|c|c|c|}
\hline \multicolumn{10}{|c|}{ Telomere length categories } \\
\hline <P1 & P1-P2.5 & P2.5-P5 & P5-P10 & P10-P50 & $\begin{array}{c}\text { Around } \\
\text { P50 }\end{array}$ & P50-P90 & P90-P95 & $\begin{array}{c}\text { P95- } \\
\text { P97.5 }\end{array}$ & $\begin{array}{c}\text { P97.5- } \\
\text { P99 }\end{array}$ & $>$ P99 \\
\hline
\end{tabular}

B

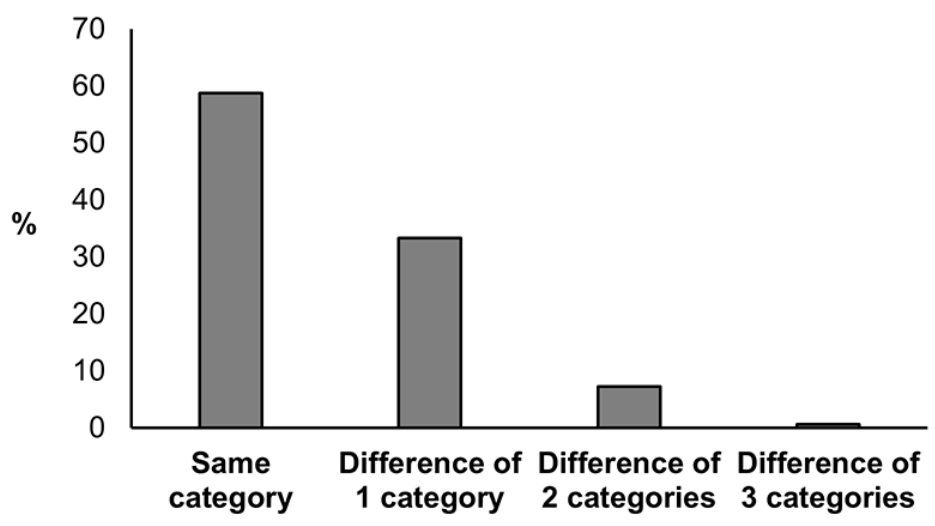

Supplementary Figure 1. Telomere length is consistent in lymphocytes and granulocytes. TL is categorized as described in (A). When we compared TL in lymphocytes and granulocytes of patients from our cohort, more than $90 \%$ of patients had no (58.7\%) or only one (33.3\%) category difference in TL (B). 